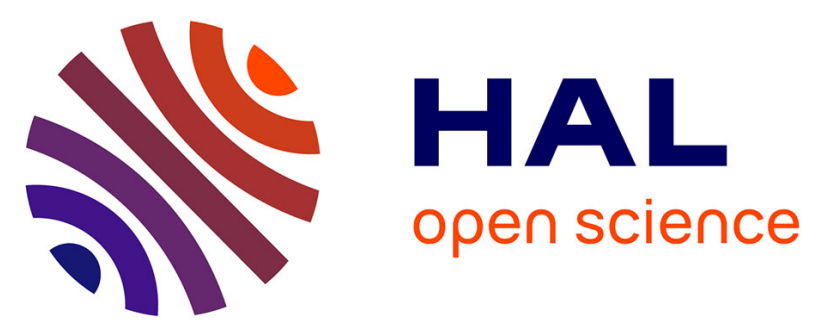

\title{
Switching from abacavir/lamivudine plus nevirapine to abacavir/lamivudine/dolutegravir in virologically controlled HIV-infected adults (SWAD study)
}

C. Allavena, C. Volteau, E. André-Garnier, T. Guimard, N. Hall, L. Khatchatourian, M. Morrier, E. Billaud, A. Rodallec, V. Reliquet, et al.

\section{To cite this version:}

C. Allavena, C. Volteau, E. André-Garnier, T. Guimard, N. Hall, et al.. Switching from abacavir/lamivudine plus nevirapine to abacavir/lamivudine/dolutegravir in virologically controlled HIV-infected adults (SWAD study). Médecine et Maladies Infectieuses, 2019, 49, pp.505 - 510. 10.1016/j.medmal.2018.11.012 . hal-03488177

\section{HAL Id: hal-03488177 \\ https://hal.science/hal-03488177}

Submitted on 21 Dec 2021

HAL is a multi-disciplinary open access archive for the deposit and dissemination of scientific research documents, whether they are published or not. The documents may come from teaching and research institutions in France or abroad, or from public or private research centers.
L'archive ouverte pluridisciplinaire HAL, est destinée au dépôt et à la diffusion de documents scientifiques de niveau recherche, publiés ou non, émanant des établissements d'enseignement et de recherche français ou étrangers, des laboratoires publics ou privés.

\section{(ㄷ)(1) $\$$}

Distributed under a Creative Commons Attribution - NonCommerciall 4.0 International 


\section{Abacavir/lamivudine/dolutégravir après abacavir/lamivudine plus névirapine chez des adultes infectés par le VIH et contrôlés virologiquement (étude SWAD)}

\section{Switching from abacavir/lamivudine plus nevirapine to abacavir/lamivudine/dolutegravir in virologically controlled HIV-infected adults (SWAD study)}

C Allavena ${ }^{1,2}$, C Volteau ${ }^{3}$, E André-Garnier ${ }^{2,4}$, T Guimard ${ }^{5}$, N Hall ${ }^{1}$, L Khatchatourian ${ }^{1}$, M Morrier ${ }^{4}$, E

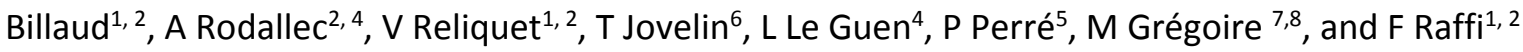

Service de maladies infectieuses et tropicales, CHU Nantes, Nantes, France

2 INSERM UIC 1413, CHU Nantes, France

${ }^{3}$ Plateforme de Biométrie, CHU Nantes, Nantes, France Service de virologie, CHU Nantes, Nantes, France

${ }^{5}$ Service de médecine interne, CHD Vendée, La Roche sur Yon, France

${ }^{6}$ COREVIH Pays de la Loire, CHU Nantes, Nantes, France

${ }^{7}$ Service de pharmacologie clinique, CHU Nantes, Nantes, France

EA 3826 Thérapeutiques Cliniques et Expérimentales des Infections, Université de Nantes, Nantes, France

\section{Corresponding author}

Dr. Clotilde Allavena

Service de Maladies Infectieuses et Tropicales, CHU Nantes, 1 Place Alexis-Ricordeau, 44000 Nantes, France. Tel: +33 2400830 99, Fax: +33 2400831 81. email: Clotilde.allavena@chu-nantes.fr Mots clés : dolutégravir ; traitement de maintenance ; infection par le VIH

\section{Résumé}

Highlights

- $\quad$ The SWAD study shows that switching from nevirapine to dolutegravir in combination with abacavir/lamivudine in 53 HIV-infected virologically controlled subjects is a well-tolerated and effective strategy. Virologic suppression was sustained over the 48 weeks of follow-up despite an initially transient pharmacokinetic interaction resulting in a moderate decrease in dolutegravir exposure, with plasma concentrations still above IC90. Subjects were satisfied with the switch to a single tablet regimen without food restraint.

Introduction. Les voies métaboliques du dolutégravir suggèrent un effet prédateur potentiel de la névirapine sur la pharmacocinétique du dolutégravir et le switch de névirapine vers dolutégravir pourrait entraîner une exposition sous-optimale du dolutégravir plusieurs semaines après l'arrêt de névirapine. 
Patients et méthodes. Étude prospective, pilote, ouverte, non comparative et bicentrique pour évaluer la pharmacocinétique, l'efficacité virologique, la tolérance et la satisfaction du patient après switch d'abacavir/lamivudine plus névirapine vers un comprimé unique

d'abacavir/lamivudine/dolutégravir. Le critère d'évaluation principal était le maintien de la suppression virologique (ARN VIH-1 $<50$ copies $/ \mathrm{mL}$ ) à S12. Les critères secondaires étaient suppression virologique à $S 48$, tolérance, satisfaction du patient et évaluation de l'interaction pharmacocinétique. Cinquante-trois adultes sous abacavir/lamivudine et névirapine depuis 6 ans en médiane et contrôlés virologiquement depuis 9,6 ans ont été inclus.

Résultats. La concentration stable de dolutégravir a été atteinte entre 4 et 12 semaines alors qu'elle était attendue entre 5 et 10 jours. Tous les patients ont gardé une charge virale indétectable aux semaines 12 et 48 . Abacavir/lamivudine/dolutégravir a été globalement bien toléré, avec deux cas d'événements indésirables graves jugés non liés aux médicaments de l'étude (syndrome coronarien dans les deux cas) et un arrêt pour insuffisance rénale à la semaine 24 avec une légère amélioration après interruption du dolutégravir. Le niveau de satisfaction du traitement, déjà élevé à l'inclusion, s'est amélioré après le switch.

Conclusion. L'effet prédateur transitoire de la névirapine sur le dolutégravir n'a eu aucune conséquence clinique ni virologique. La satisfaction du patient s'est améliorée avec le comprimé unique. 


\section{Abstract}

Introduction. The metabolic pathways of dolutegravir suggest a potential predator effect of nevirapine on dolutegravir pharmacokinetics and switching from a nevirapine- to a dolutegravir-containing regimen could lead to a lower and suboptimal exposure to dolutegravir several weeks after the switch in case of persistent inducer effect.

Patients and method. Prospective, pilot, single-arm, open-label, non-comparative, bicentric study to evaluate the pharmacokinetics, virologic outcomes, safety, and patient satisfaction of switching from abacavir/lamivudine and nevirapine to a single tablet of abacavir/lamivudine/dolutegravir. The primary endpoint was the maintenance of virologic suppression (HIV-1 RNA $<50$ copies $/ \mathrm{mL}$ ) at week 12. Secondary endpoints were virologic suppression at week 48 , safety and tolerability, patient satisfaction, and pharmacokinetic interaction between nevirapine and dolutegravir. Fifty-three adults on stable abacavir/lamivudine and nevirapine regimen for a median duration of 6 years and virologically suppressed for 9.6 years were included.

Results. Dolutegravir reached steady state by week $4 /$ week 12 when expected by day $5 /$ day 10 . All subjects maintained plasma HIV-RNA $<50$ copies $/ \mathrm{mL}$ at week 12 and week 48 . Abacavir/lamivudine/dolutegravir was well-tolerated, with two cases of serious adverse events deemed unrelated to study drugs (coronary syndrome in both cases), and one discontinuation for renal impairment at week 24 with a slight improvement after dolutegravir discontinuation. Level of treatment satisfaction remained high after the switch.

Conclusion. The transient predator effect of nevirapine on dolutegravir had no clinical consequences after switching from nevirapine to dolutegravir, neither on safety nor maintenance of virologic suppression. It also had no consequences on patient satisfaction.

Keywords: dolutegravir; maintenance therapy; HIV infection 


\section{Introduction}

Combination antiretroviral therapy (CART) has considerably improved in recent years and is associated with durable response due to the high rate of maintenance of virologic suppression and good longterm safety profile [1]. Once viral suppression is obtained with cART, the main objective is to maintain success in the long-term, to improve quality of life for patients by avoiding long-term toxicities and facilitating convenience and patient compliance using regimens with a good tolerability profile and the lowest pill burden. Patients on suppressive CART may be candidates for regimen simplification if they are currently on a regimen prescribed prior to the availability of newer options or formulations that might be easier to administer and/or better tolerated [2].

Dolutegravir is the third integrase inhibitor approved for use in HIV-1-infected subjects and is available as a single tablet co-formulated with two nucleosides, abacavir and lamivudine $[3,4]$. Thus, in patients on long-term treatment with nevirapine-containing therapy, switching to dolutegravir (single tablet regimen) might further improve convenience and compliance while preserving the efficacy, tolerability, and lipid profile.

The metabolic pathways of dolutegravir and nevirapine suggest a potential pharmacokinetic interaction between these drugs, and switching from a nevirapine to a dolutegravir-containing regimen could lead to a lower and suboptimal exposure to dolutegravir in relation to the inducer effect of nevirapine on UGT1A1, which is the first metabolic pathway of dolutegravir but also on CYP3A4 or Pgp which usually represent its minor metabolic pathways [5]. However, this transient post-switch lower drug exposure could be compensated by the long half-life of nevirapine which could maintain sufficient exposure to provide an efficient HIV replication blockade. In this pilot study, undertaken to establish the efficacy of such nevirapine-dolutegravir switch, we evaluated the pharmacokinetics, virologic outcomes, safety, and patient's satisfaction of switching from abacavir/lamivudine and nevirapine to abacavir/lamivudine/dolutegravir single tablet. Results of a pharmacokinetics sub-study 
have been previously published [6]. Other endpoints including maintenance of virologic suppression, safety, tolerability, and treatment satisfaction over 48 weeks are presented in this article.

\section{Patients and methods}

We performed a prospective, single-arm, open-label, non-comparative, bicentric study registered at ClinicalTrials.gov under identifier NCT02067767, to investigate the virologic safety, the clinical and laboratory tolerability, and the pharmacological pattern of the substitution of a triple therapy with abacavir/lamivudine and nevirapine $(600 \mathrm{mg} / 300 \mathrm{mg}+400 \mathrm{mg}$ once daily $)$ to abacavir/lamivudine/dolutegravir (600 mg/300 mg/50 mg once daily). The study was performed in accordance with the Declaration of Helsinki and approved by the ethics committee. All subjects gave written informed consent. Eligible subjects were HIV-1-infected adult patients receiving a stable abacavir/lamivudine and nevirapine regimen for more than six months, who had maintained virologic suppression with a plasma HIV-1 viral load below 50 copies/ml for more than 12 months, with no history of prior virologic failure on antiretroviral therapy, with a HLA B*5701 negative test, and who were willing to change their current regimen for convenience reason. The main exclusion criteria were concomitant therapy with anti-H2 or antacids or with drugs contraindicated with dolutegravir [4], any prior exposure to integrase inhibitor, any major IAS-USA mutation conferring resistance to one or more of reverse transcriptase or integrase inhibitors on any historical plasma genotype if available, hepatic cytolysis (ALT five times above the upper normal limit), and estimated glomerular filtration rate - using the re-expressed modification of diet in renal disease (MDRD) for standardized serum creatinine below $60 \mathrm{~mL} / \mathrm{min}$. For women of childbearing potential an adequate mechanical contraception was needed, and they were asked not to plan pregnancy during the study period.

Clinical and laboratory features were assessed at screening, baseline, and weeks 1, 2, 4, 12, 24, 36, and 48. Treatment satisfaction was evaluated with the HIV treatment satisfaction questionnaires (HIVTSQ), i.e. "HIV Treatment Satisfaction Questionnaire status version" (HIVTSQs) at baseline and week 48 and 
"HIV Treatment Satisfaction Questionnaire change version" (HIVTSQc) at week 12 to overcome potential ceiling effects $[7,8]$.

A PK study was conducted in parallel to evaluate dolutegravir trough concentrations (C0), as well as nevirapine residual concentrations over 12 weeks. Dolutegravir and/or nevirapine plasma concentrations were measured at switch and at week 1 , week 2 , week 4 , and week 12 by liquid chromatography coupled with a mass spectrometry method which has been validated as per FDA guidelines $[9,10]$. Only CO (24h $\pm 4 \mathrm{~h}$ after intake) were retained for PK study. IC90 of dolutegravir $(64 \mathrm{ng} / \mathrm{mL})$ was chosen as the pharmacodynamics target

Characteristics of patients were described using either median with interquartile range for continuous variables or frequency for categorical variables.

The primary endpoint was maintenance of virologic suppression (HIV-1 RNA $<50$ copies $/ \mathrm{mL}$ ) at week 12. Secondary endpoints were virologic suppression at week 48 , safety and tolerability, patient satisfaction, and pharmacokinetic interaction between nevirapine and dolutegravir

\section{Results}

Fifty-three subjects were included in the study between February 2014 and December 2014. Baseline characteristics are presented in Table 1. Patients were on cART with a median duration of viral suppression of 9.6 years and were receiving an abacavir/lamivudine and nevirapine regimen for a median duration of 6 years.

At week 12 and week 48 all patients maintained plasma HIV-1 RNA below 50 copies $/ \mathrm{mL}$. At week 24 one patient had a blip with a viral load at 53 copies $/ \mathrm{mL}$, controlled below 20 copies $/ \mathrm{mL}$ two weeks later. Plasma HIV-RNA dosage was below the threshold with no detected target in $83 \%, 77 \%$, and $67 \%$ of patients at baseline, week 24, and week 48 , respectively. Baseline median CD4 was 737 cells $/ \mathrm{mm}^{3}$, with a median gain of 35 and 14 cells $/ \mathrm{mm}^{3}$ at week 24 and week 48 , respectively.

Abacavir/lamivudine/dolutegravir was overall well tolerated. Two serious adverse events occurred during the follow-up, deemed unrelated to the study regimen by the investigator (coronary syndrome 
in two cases at week 11 and week 47, respectively). One patient discontinued the study regimen at week 24 for renal impairment with an eGFR (MDRD) that decreased from $99 \mathrm{~mL} / \mathrm{min}$ at baseline to $60 \mathrm{~mL} / \mathrm{min}$ at week 24. He was then switched back to abacavir/lamivudine plus nevirapine with a slight improvement of the renal function.

Between baseline and week 48 , the lipid profile slightly improved with a median [interquartile] decrease of $-0.11 \mathrm{~g} / \mathrm{L}[-0.23 ; 0.11]$ for triglycerides, $-0.25 \mathrm{~g} / \mathrm{L}[-0.54 ;-0.12]$ for total cholesterol, $-0.11 \mathrm{~g} / \mathrm{L}$ [-0.31;0.01] for LDL cholesterol, and $-0.09 \mathrm{~g} / \mathrm{L}[-0.17 ;-0.04]$ for HDL cholesterol. After a median decrease in glomerular filtration rate estimated by the MDRD formula between baseline and week 4 of $-6 \mathrm{~mL} / \mathrm{min}[-17 ; 0]$, the median decrease was stable during follow-up at $-11 \mathrm{~mL} / \mathrm{min}[-20 ;-6]$ at week 24 and $-9 \mathrm{~mL} / \mathrm{min}[-19 ;-1]$ at week 48 . Urine protein/creatinine ratio did not change over 48 weeks (decrease of $-0.08[-2.63 ; 1.41]$ ). Two subjects had a transient grade 2 ALT elevation at week 4 and week 24 that both spontaneously resolved.

Forty-three patients were included in the 12-weeks PK study. Mean dolutegravir CO [Standard Deviation (SD), number of subjects (n)] were $666 \mathrm{ng} / \mathrm{mL}[355 ; 35]$ at week $1,947 \mathrm{ng} / \mathrm{mL}[585 ; 38]$ at week 2, 1,130 ng/mL [571; 38] at week 4, and 1,439 ng/mL [923; 38] at week 12 (Figure 1). All patients were maintained above dolutegravir IC90 $(64 \mathrm{ng} / \mathrm{mL})$ at all sample times. Mean nevirapine concentrations [SD, n] were $3,435 \mathrm{ng} / \mathrm{mL}[1,063 ; 35]$ at switch, $43 \mathrm{ng} / \mathrm{mL}[107 ; 35]$ at week $1,1 \mathrm{ng} / \mathrm{mL}$ [8; 38] at week 2 and were undetectable at week 4 and week 12 . Nevirapine terminal half-life after switch was 27 hours. All patients were maintained above nevirapine IC90 (40 ng/mL) at switch [11]. At week 1, 27/35 patients were measured below nevirapine IC90 and 38/38 at week 2. Dolutegravir concentrations achieved steady state after at least four weeks of treatment because of nevirapine persistent inducing effect.

Results from self-questionnaires HIVTSQs and HIVTSQc are presented in Table 2. The overall median general satisfaction/clinical score (range 0-30) and lifestyle/ease score (range 0-30) were 28 and 27 at baseline, and 29 and 29 at week 48, respectively. At week 12, the relative change in satisfaction improved for all items when comparing the new treatment (abacavir/lamivudine/dolutegravir) with 
the previous one (abacavir/lamivudine + nevirapine). Both the score of general satisfaction/clinical score and the score of lifestyle/ease score improved with a median score of $+12 / 15$ and $+12 / 15$, respectively.

\section{Discussion}

Our study is one of the very few studies evaluating a switch from a non-nucleoside reverse transcriptase inhibitors (NNRTI) - nevirapine or efavirenz - to dolutegravir. We showed that replacing nevirapine by dolutegravir, when combined with abacavir/lamivudine, seemed safe and effective over 48 weeks, although our study was not designed to confirm this hypothesis. In the recently published STRIIVING study, $31 \%$ of the 553 included subjects were switched from a regimen with two nucleoside reverse transcriptase inhibitors (NRTI) + one NNRTI to abacavir/lamivudine/dolutegravir with high and similar efficacy and tolerability results [12]. Within the class of integrase strand transfer inhibitors (INSTI), the STRATEGY-NNRTI study demonstrated that switching from FTC/TDF + NNRTI to elvitegravir/cobicistat/FTC/TDF was effective and safe [13]. Furthermore, in our study, only one compound among the regimen was substituted: a higher genetic barrier drug, i.e. dolutegravir, was substituted for a lower genetic barrier drug, i.e. nevirapine. After switching from abacavir/lamivudine + nevirapine to abacavir/lamivudine/dolutegravir, dolutegravir reached steady state by week 4/week 12 when expected by day 5/day10 [6]. This observation could be explained by an induction of UGT1A1 but also CYP3A4 and Pgp, persisting one month after nevirapine discontinuation [14]. All patients were maintained above dolutegravir IC90 at all sample times. Moreover, the terminal half-life of nevirapine after the switch was comparable to expected values [6]. Despite this pharmacokinetic interaction, the observed decrease in dolutegravir exposure in combination with nevirapine was limited and had no clinical nor virologic negative consequence [6]. Final results, at 48 weeks, provide further information on the excellent virologic response, with no confirmed failure, and favorable safety profile of this nevirapine-dolutegravir switch. Following dolutegravir initiation, patients had small mean increases in serum creatinine that were evident by week 2 and remained stable through 48 weeks. This result was expected as dolutegravir inhibits the organic cation transporter OCT2 and the multidrug and toxin 
extrusion protein MATE 1, similarly to other drugs such as cobicistat, trimethoprim, or cimetidine, which decrease tubular secretion of creatinine and therefore increase serum creatinine concentrations without affecting glomerular filtration $[15,16]$. We observed no evidence of clinically significant changes over 48 weeks in the fasting lipid profile after switching from nevirapine to dolutegravir. This result was expected based on the lipid-friendly profile of both drugs $[17,18]$.

The study population includes highly compliant patients, with prior long-term sustained virologic suppression on a two pills-once a day nevirapine regimen and with a high baseline level of treatment satisfaction (54/60). However, patients agreed to participate in the study for convenience reason, i.e. to decrease pill burden for a single tablet regimen with similar absence of food constraint. One year after switching, the level of satisfaction remained high (58/60). By simply reducing the number of pills from two pills once daily to a well-tolerated single tablet regimen, we even observed satisfaction improvement 12 weeks after the switch. We can consider that the improvement in treatment satisfaction is mainly due to treatment simplification for a one pill-once a day regimen. These results are reassuring for the long-term efficacy of the single tablet regimen as there is an association between satisfaction of HIV-infected patients with their treatment and compliance with CART [19, 20]. We cannot exclude perception bias as patients' perception, even before switching, and personal beliefs can modulate and influence the perceived efficacy of new treatment, health improvement, and adverse events, translating into higher satisfaction with the new therapy [21]. Our results are in accordance with those of the randomized STRIVIING study, where virologically suppressed patients who switched for abacavir/lamivudine/dolutegravir were more satisfied with their treatment at week 24 compared with patients who did not change treatment [12].

Our study has strengths and limitations. This is the first prospective study to evaluate the PK, efficacy, safety, and satisfaction of substituting dolutegravir for nevirapine, and the first to evaluate abacavir/lamivudine/dolutegravir as a single tablet regimen. Limitations of the study are the absence of a control arm, the relatively limited sample size, and the bias of patients who agreed to participate to receive the new single tablet regimen of abacavir/lamivudine/dolutegravir, not yet commercially 
available at the time of the study. Triumeq ${ }^{\circledR}$ (abacavir/lamivudine/dolutegravir) was available in France in June 2015, while subjects were included in the study before December 2014 and, compared with the other single tablet regimens, Triumeq ${ }^{\circledR}$ has the advantage of being the only combination regimen with abacavir/lamivudine [22]. Studies involving a switching strategy tend to attract patients motivated by a treatment change. Patients reported clinical outcomes, and satisfaction evaluation might be biased by the motivation to switch therapy. As a consequence a possible bias could favor the switch option under evaluation.

\section{Conclusion}

Switching from nevirapine to dolutegravir, while maintaining the nucleosides backbone of abacavir/lamivudine, was safe and resulted in sustained viral suppression. The transient pharmacokinetic interaction had no clinical consequences, neither on safety nor on the sustained virologic suppression. Although baseline satisfaction was high, it remained high and even improved after switching for a one pill-once a day regimen without food constraint.

\section{Declaration of interests}

CA, EB, EAG, and PP have received speaking honoraria or travel grants from ViiV Healthcare, MSD, Janssen, and Gilead. MG has received travel grants from ViiV Healthcare and Janssen. AR has received travel grants from Janssen. TG has received travel grants from ViiV Healthcare and Gilead. FR has received research funding or honoraria from or consulted for AbbVie, Bristol-Myers Squibb, Gilead Sciences, Janssen, MSD, ViiV Healthcare. All other authors report no competing interests.

\section{Funding}

This study was sponsored by a grant from ViiV Healthcare, who had no role in data collection and data analysis.

\section{Acknowledgements}

The authors would like to thank participants, their partners and families, all the investigators and their study staff for the SWAD study, and ViiV Healthcare for its financial support. 


\section{Authors' contribution}

CA and FR contributed to the study design, acquisition, analysis, and interpretation of data and contributed to writing the article. CV served as the study statistician; she contributed to the study design, acquisition, analysis, and interpretation of data and contributed to drafting and revising the article. TG, NH, LK, MM, EB, VR, and PP were study investigators and were involved in the recruitment and follow-up of participants during the study and contributed to data collection. TJ served as data manager. EAG, AR, and LL served as clinical virologists. MG served as the clinical pharmacologist. All authors provided input to the report and approved the final version of the article.

List of investigators: E. Billaud, V. Reliquet, C. Allavena, C. Brunet-Cartier, B. Bonnet, P. Morineau-Le Houssine, S. Bouchez, M. Lefebvre, D. Boutoille, S. Pineau, C. Biron, M. Besnier, F. Sauser, P. Point, O. Aubry, O. Grossi, M. Colas, R. Choquet, C. Supiot, H. Hüe, L. Larmet, J. Orain, S. Sécher-Pineau, T. Jovelin, N. Hall, C. Bernaud, F. Vivrel, L. Khatchatourian, M. Cavellec, A. Rodallec, L. Le Guen, E. AndréGarnier, V. Ferré (Nantes), P. Perré, T. Guimard, S. Léautez, M. Morrier, J.L. Esnault, O. BollengierStragier, I. Suaud, L. Lainé, H. Durand, C. Garnier (la Roche sur Yon) 
1. Young J, Psichogiou M, Meyer L, Ayayi S, Grabar S, Raffi F, et al. CD4 cell count and the risk of AIDS or death in HIV-Infected adults on combination antiretroviral therapy with a suppressed viral load: a longitudinal cohort study from COHERE. PLOS Med 2012,9:e1001194.

2. Gunthard HF, Saag MS, Benson CA, del Rio C, Eron JJ, Gallant JE, et al. Antiretroviral Drugs for Treatment and Prevention of HIV Infection in Adults: 2016 Recommendations of the International Antiviral Society-USA Panel. JAMA 2016,316:191-210.

3. McCormack PL. Dolutegravir: a review of its use in the management of HIV-1 infection in adolescents and adults. Drugs 2014,74:1241-1252.

4. Triumeq. Summary of Product Characteristics. In; 2014.

5. Castellino S, Moss L, Wagner D, Borland J, Song I, Chen S, et al. Metabolism, excretion, and mass balance of the HIV-1 integrase inhibitor dolutegravir in humans. Antimicrob Agents Chemother 2013,57:3536-3546.

6. Dailly E, Allavena C, Gregoire M, Reliquet V, Bouquie R, Billaud E, et al. Influence of nevirapine administration on the pharmacokinetics of dolutegravir in patients infected with HIV-1. J Antimicrob Chemother 2015,70:3307-3310.

7. Woodcock A, Bradley C. Validation of the HIV treatment satisfaction questionnaire (HIVTSQ). Qual Life Res 2001,10:517-531.

8. Woodcock A, Bradley C. Validation of the revised 10-item HIV Treatment Satisfaction Questionnaire status version and new change version. Value Health 2006,9:320-333.

9. Gregoire M, Deslandes G, Renaud C, Bouquie R, Allavena C, Raffi F, et al. A liquid chromatography-tandem mass spectrometry assay for quantification of rilpivirine and dolutegravir in human plasma. J Chromatogr B Analyt Technol Biomed Life Sci 2014,971:1-9.

10. Martin J, Deslandes G, Dailly E, Renaud C, Reliquet V, Raffi F, Jolliet P. A liquid chromatography-tandem mass spectrometry assay for quantification of nevirapine, indinavir, atazanavir, amprenavir, saquinavir, ritonavir, lopinavir, efavirenz, tipranavir, 
darunavir and maraviroc in the plasma of patients infected with HIV. J Chromatogr B Analyt Technol Biomed Life Sci 2009,877:3072-3082.

11. Cortez JM, Jr., Quintero R, Moss JA, Beliveau M, Smith TJ, Baum MM. Pharmacokinetics of injectable, long-acting nevirapine for HIV prophylaxis in breastfeeding infants. Antimicrob Agents Chemother 2015,59:59-66

12. Trottier B LJ, Logue $\mathrm{K}$, et al. . Switching to abacavir/dolutegravir/lamivudine fixed dose combination (ABC/DTG/3TC FDC) from a PI, INI or NNRTI based regimen maintains HIV suppression. In: 55th Interscience Conference of Antimicrobial Agents and Chemotherapy (ICAAC). San Diego, California; September 17-21, 2015.

13. Pozniak A, Flamm J, Antinori A, Bloch M, Ward D, Berenguer J, et al. Switching to the singletablet regimen of elvitegravir, cobicistat, emtricitabine, and tenofovir DF from nonnucleoside reverse transcriptase inhibitor plus coformulated emtricitabine and tenofovir DF regimens: Week 96 results of STRATEGY-NNRTI. HIV Clin Trials 2017,18:141-148.

14. Reese MJ, Savina PM, Generaux GT, Tracey H, Humphreys JE, Kanaoka E, et al. In vitro investigations into the roles of drug transporters and metabolizing enzymes in the disposition and drug interactions of dolutegravir, a HIV integrase inhibitor. Drug Metab Dispos 2013,41:353-361.

15. Stellbrink HJ, Reynes J, Lazzarin A, Voronin E, Pulido F, Felizarta F, et al. Dolutegravir in antiretroviral-naive adults with HIV-1: 96-week results from a randomized dose-ranging study. AIDS 2013,27:1771-1778.

16. Koteff J, Borland J, Chen S, Song I, Peppercorn A, Koshiba T, et al. A phase 1 study to evaluate the effect of dolutegravir on renal function via measurement of iohexol and paraaminohippurate clearance in healthy subjects. Br J Clin Pharmacol 2013,75:990-996.

17. van der Valk M, Kastelein JJ, Murphy RL, van Leth F, Katlama C, Horban A, et al. Nevirapinecontaining antiretroviral therapy in HIV-1 infected patients results in an anti-atherogenic lipid profile. AIDS 2001,15:2407-2414. 
18. Raffi F, Rachlis A, Stellbrink HJ, Hardy WD, Torti C, Orkin C, et al. Once-daily dolutegravir versus raltegravir in antiretroviral-naive adults with HIV-1 infection: 48-week results from the randomised, double-blind, non-inferiority SPRING-2 study. Lancet 2013,381:735-743.

19. Nachega JB, Parienti JJ, Uthman OA, Gross R, Dowdy DW, Sax PE, et al. Lower pill burden and once-daily antiretroviral treatment regimens for HIV infection: A meta-analysis of randomized controlled trials. Clin Infect Dis 2014,58:1297-1307.

20. Ammassari A, Trotta MP, Murri R, Castelli F, Narciso P, Noto P, et al. Correlates and predictors of adherence to highly active antiretroviral therapy: overview of published literature. J Acquir Immune Defic Syndr 2002,31 Suppl 3:S123-127.

21. Casado JL, Marin A, Romero V, Banon S, Moreno A, Perez-Elias MJ, et al. The influence of patient beliefs and treatment satisfaction on the discontinuation of current first-line antiretroviral regimens. HIV Med 2016,17:46-55.

22. Journal officiel de la République Française n0132. Arrêté du 8 Juin 2015 modifiant l'arrêté du 17 décembre 2004 modifié fixant la liste prévue à l'article L.5126-4 de code de la santé publique. 